\title{
Controlling Cyclic Epidemics on the Crops of the Agroecosystems: Articulate all the Dimensions in the Formalisation, but Look for a Local Solution
}

\author{
Lydia Bousset and Anne-Marie Chèvre \\ INRA, UMR1349 IGEPP, 35653 Le Rheu, France \\ Correspondence should be addressed to Lydia Bousset, lydia.bousset@rennes.inra.fr \\ Received 30 September 2011; Revised 27 January 2012; Accepted 10 February 2012 \\ Academic Editor: Gaoming Jiang
}

Copyright ( 92012 L. Bousset and A.-M. Chèvre. This is an open access article distributed under the Creative Commons Attribution License, which permits unrestricted use, distribution, and reproduction in any medium, provided the original work is properly cited.

In agroecosystems, crop yield is reduced by epidemics. At the field scale, epidemiology succeeded knowledge percolation across theory, empirical studies, and recommendations to actors. Achieving similar success at the landscape level requires understanding of ecosystems. The aim of this manuscript is to formalize cyclic epidemics, in which development depends on interaction in space and in time between host plants, pathogens, environment, and human actions. In agroecosystems, human actions exacerbate homogeneities alternating with sharp discontinuities on scales of time and space. The dynamics of cyclic epidemics takes discontinuities into account. This allows decomposing control at the field and at the landscape scales into goals to reach, corresponding to the components of the pluriannual dynamics of epidemics. Articulating disciplinary concepts open the prospect of optimization by identification of one's potential contributions. Finally, we propose that cyclic epidemics could be controlled by looking for a local solution, in a decentralized manner.

\section{Introduction: The Need to Formalize Epidemics in order to Control Them}

An ecosystem is defined as "a dynamic complex of plant, animal, and microorganism communities and their nonliving environment interacting as a functional unit" [1]. Thus in the broadest sense, an "agroecosystem" includes all managed and unmanaged environments, domesticated and wild communities, including human communities [2]. In agroecosystems, plant populations are organised as crops, managed towards the goal of production. Epidemics reduce crop yield, and current disease control is questioned $[3,4]$. This implies reconsidering disease control by making explicit the ecology of agroecosystems. Under the light of epidemiological knowledge, articulating the contributions of scientific disciplines is needed because the development of epidemics depends on the interaction in space and in time between host plants, pathogens, environment, and human actions [5].
At the field scale, epidemiology succeeded knowledge percolation across theory, empirical studies, and recommendations to actors. This success in rooted on a clear theoretical formalization, disease foci, and their growth in time and in space [6], that allowed modelling [7] prompted empirical studies $[8,9]$ and allowed links to other disciplines. The results of epidemiological studies on the modulation of quantitative growth of foci depending on the climate [10] on the differentiation of pathogens into pathotypes [11] and on quantitative resistance [12] have been translated into guidelines for action in decision support models [13], into surveys of pathogen populations [14], into recommendations for varietal mixtures [15], and into breeding strategies [16-18].

At the landscape scale, Zadoks [19] referring to diversity within and between crops wrote "diversity may be amenable to management," and empirical studies support this affirmation, for example, by spatial diversification of varieties [15]. However, strategies derived from epidemiology at the field 


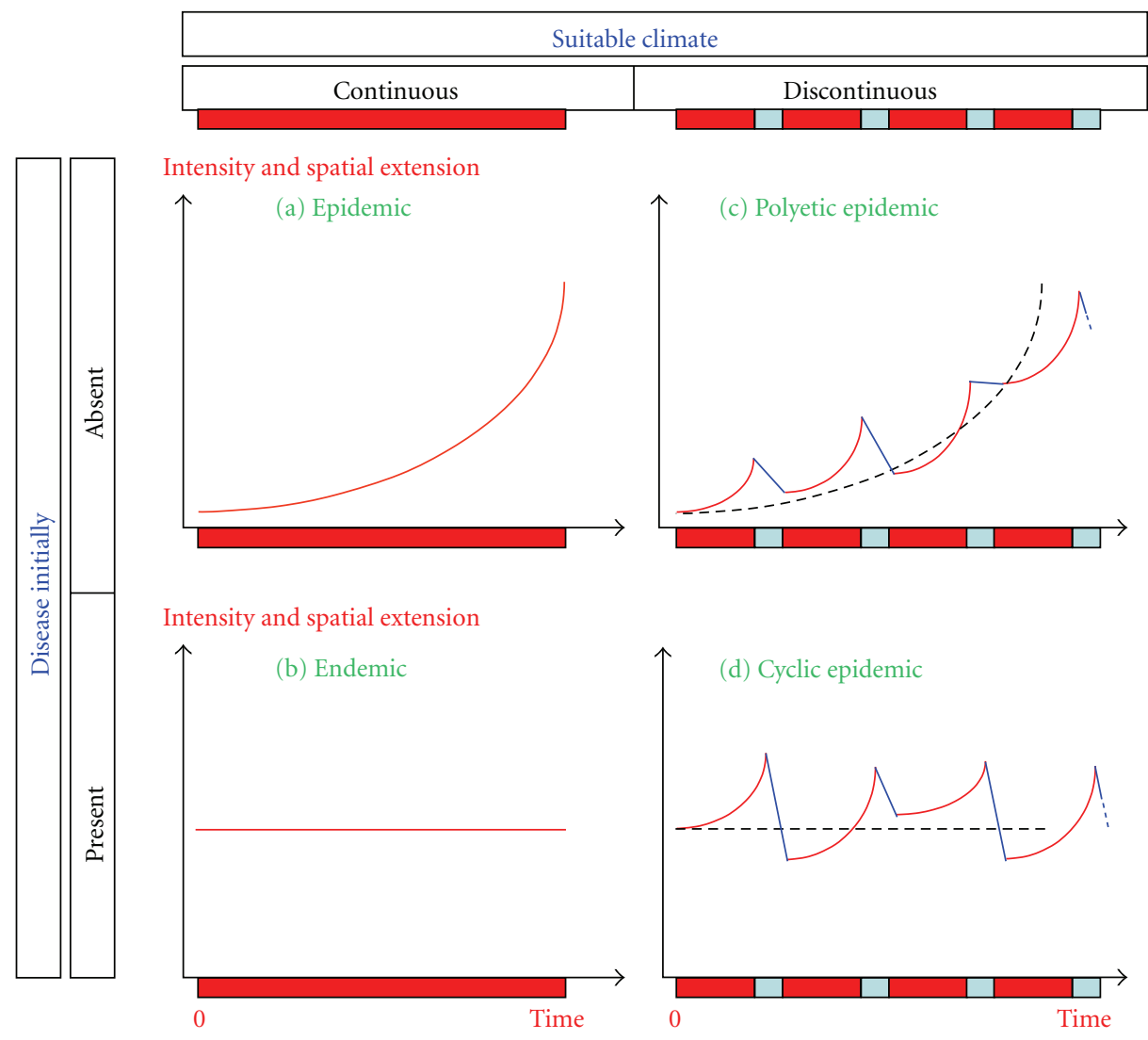

FIGURE 1: Schematic representation of the four types of disease dynamics given the initial presence of the disease and the suitability of the climate. When the climate is suitable continuously, initial absence or presence of the disease contrasts: (a) epidemic and (b) endemic, respectively. When the increase of the disease is discontinuous on short-term time scale, dynamics over long-term time scale contrasts: (c) polyetic epidemic and (d) cyclic epidemic, respectively.

scale still outnumber actions at the landscape scale $[4,20$, 21]. Actual constraints render urgent to follow the recommendations to consider scales wider than one field during one growing season [22] to develop spatial epidemiology [23], landscape epidemiology [24], and to change cropping practices at the landscape scale [25]. This requires coming back to the definition of different types of disease dynamics, to clarify what has been achieved and what remains to be done.

The initial presence of the disease and the continuity of climate's suitability contrast four types of disease dynamics, and we will recall their definitions (Figure 1).

(i) When the disease is initially absent and is initiated by allo-inoculum (i.e., inoculum issued from outside the considered field or area), then its intensity and spatial extension increase over time; we talk of an epidemic (Figure 1(a)) "The noun epidemic refers to an increase of intensity as well as extensity of the disease" [26]. As already mentioned, for this type of epidemics, realisations are numerous and allowed deducing tactics to control epidemics at the scale of the field and the cropping season. (ii) When the disease is already present at initial time, its intensity and spatial extension remain stable over time; we talk of an endemic (Figure 1(b)).

(iii) When the increase of the disease is discontinuous on short-term time scale, for example, if climate is not always suitable, seasonality inducing alternation between epidemic phases and survival phases, and the dynamics over long-term time scale is epidemic, we talk of a polyetic epidemic (Figure 1(c)) "The newer term polyetic epidemics $[\cdots]$ is limited to epidemics whose increase in intensity takes many years" [26]. Application of the polyetic epidemic concept at the landscape scale sustained research and allowed numerous and fruitful realisations ranging from theoretical works to recommendations of strategies, for example, for soil borne diseases $[22,27]$ and emergence of new diseases [28-33].

(iv) When the increase of the disease is discontinuous on short-term time scale and the dynamics over longterm time scale is endemic, we talk of a cyclic epidemic (Figure 1(d)) "If an epidemic flares up and dies down periodically, annually for instance, it is termed 
a cyclic epidemic" [26]. This is the case of many diseases that increase in spatial extension and in intensity in one field during one growing season, but neither spatial extension nor intensity increase over years at the landscape scale. These dynamics, on the long term, should neither be considered through the formalism of epidemics, nor be considered independent between successive years. To date, cyclic epidemics have been considered for humans and animals [34] and for pest outbreaks [35] but have not deserved publications for plant pathogens, and have not been submitted to a detailed formalisation.

The aim of this manuscript is to propose a conceptualisation of "cyclic epidemics" at the landscape scale, with the prospect of deducing, in agroecosystems at the scale of the landscape, options for the management of combinations of control tactics. The specificities of agroecosystems and the dynamics of cyclic epidemics are formalized in agroecosystems. The dynamics of epidemics are linked to tactics allowing for their control. Implications for optimising the efficacy of the control of epidemics are derived. Finally, these bases are exploited in terms of perspectives to achieve a solution despite the high level of complexity.

\section{What Makes Landscapes in Agroecosystems Different from Those of Natural Ecosystems?}

In natural ecosystems, it has been stressed that plant populations display complex spatial arrangements. Furthermore, they are genetically diversified and consist of plants of different ages and developmental stages [36]. Some discontinuities exist in space (host "patches") in time (seasonality) and in genetics (compatibility or not depending on the host-pathogen interaction). But as these discontinuities are not synchronised, they do not induce sharp ruptures on scales of time and space.

On the contrary, agroecosystems are characterised by the synchronised occurrence of these three discontinuities. The presence of humans-hereafter "the actors"-from which actions interact with the control of epidemics exacerbate on the one hand homogeneities and on the other hand heterogeneities, that can be summarised on scales of time and space (Figure 2 (central column)). While the continuity hypothesis is valid at the field scale, there are sharp ruptures in space when shifting from one field during one season towards one landscape during one season and in time when switching from one landscape in one season towards the same landscape in the next season. We will detail these continuities and ruptures.

One field during one growing season can be considered as a continuous and homogeneous space. Cropping towards production and harvest implies "crop management"-a set of actions interdependent at the scale of the field-following four aims. A productive cover is established, by the modification of soil structure, the sowing at controlled density, the pruning, and the weeding. The cover is maintained and supplied with elements required for growth and if necessary for flowering, by the irrigation and the fertilisation including intercrop nitrogen-trap plants. The products and coproducts are harvested, consisting of roots, leaves, stems, fruits, or seeds. The decomposition of plant-parts not exported from the field is ensured. The whole of these interdependent practices lead to homogenise the plant cover, with respect to genetics and agronomy. It includes the choice of monospecific, most often monovarietal crop, the synchronisation of plant phenology, and the synchronisation of planting and harvesting operations.

The landscape is heterogeneous in space during the cropping season, appearing as a spatial mosaic of host and nonhost "patches" (Figure 2(a)). Each patch, hereafter "field," corresponds to a cultivated field, or to natural populations of the host [37]. The rupture between fields is sharp in space. Given the limited number of cropped species, the rupture is sharp with respect to genetic compatibility; for one pathogen individual, either the whole field is host, or nonhost.

The landscape is heterogeneous in time, with the alternation of seasons and ruptures (Figure $2(\mathrm{abcd})$ ). At the scale of one farm, the "cropping systems"- attribution and rotation of species and crop management practices on a set of fields-are devised to optimise the succession of different productions on different fields. One cropping season, hereafter "season," is defined as the time span during which there are no discontinuities, neither in the host plant population, nor in the cropping system, therefore allowing for a numerical increase in the pathogen population without external input of inoculum. Cropping practices exacerbate homogeneities during the season (homogeneity at the field scale, synchronisation of cultural operations on all the fields of one species), alternating with heterogeneities (between two seasons, the cropped species can completely change on the field) in the dynamics of host and pathogen populations in time and in space.

Agroecosystems are thus characterised by continuities (each field during the season) alternating with conjunctions of sharp ruptures on scales of time and space. These ruptures lead to three kinds of discontinuities at the scale of the landscape over successive seasons. The host population size is discontinuous, with an "agronomic" cause, because, at harvest of annual plants, host availability is suppressed for pathogens, until the emergence of next season's plantlets. A spatial rupture is superimposed on the temporal rupture when the next year's crop of the same species is sown in a different field. The pathogen life cycle is discontinuous, with an "epidemiological" cause, because most of pathogens cannot develop year round, constrained by temperature or wetness duration. The composition of the pathogen population is discontinuous, with a "genetic" cause because the drastic reduction of population's numerical size due to less suitable environment, migration, sexual recombination, and change in selection pressures induce modifications in the genetic composition of the pathogen population. For endemics already occurring in the landscape, it is this alternation of continuities (suitable for the numerical and spatial increase of populations) and discontinuities (unfavourable to both increases) that produce the dynamics of cyclic epidemics. The efficiency of the control of epidemics depends on the interactions between the actors, the host population, and 


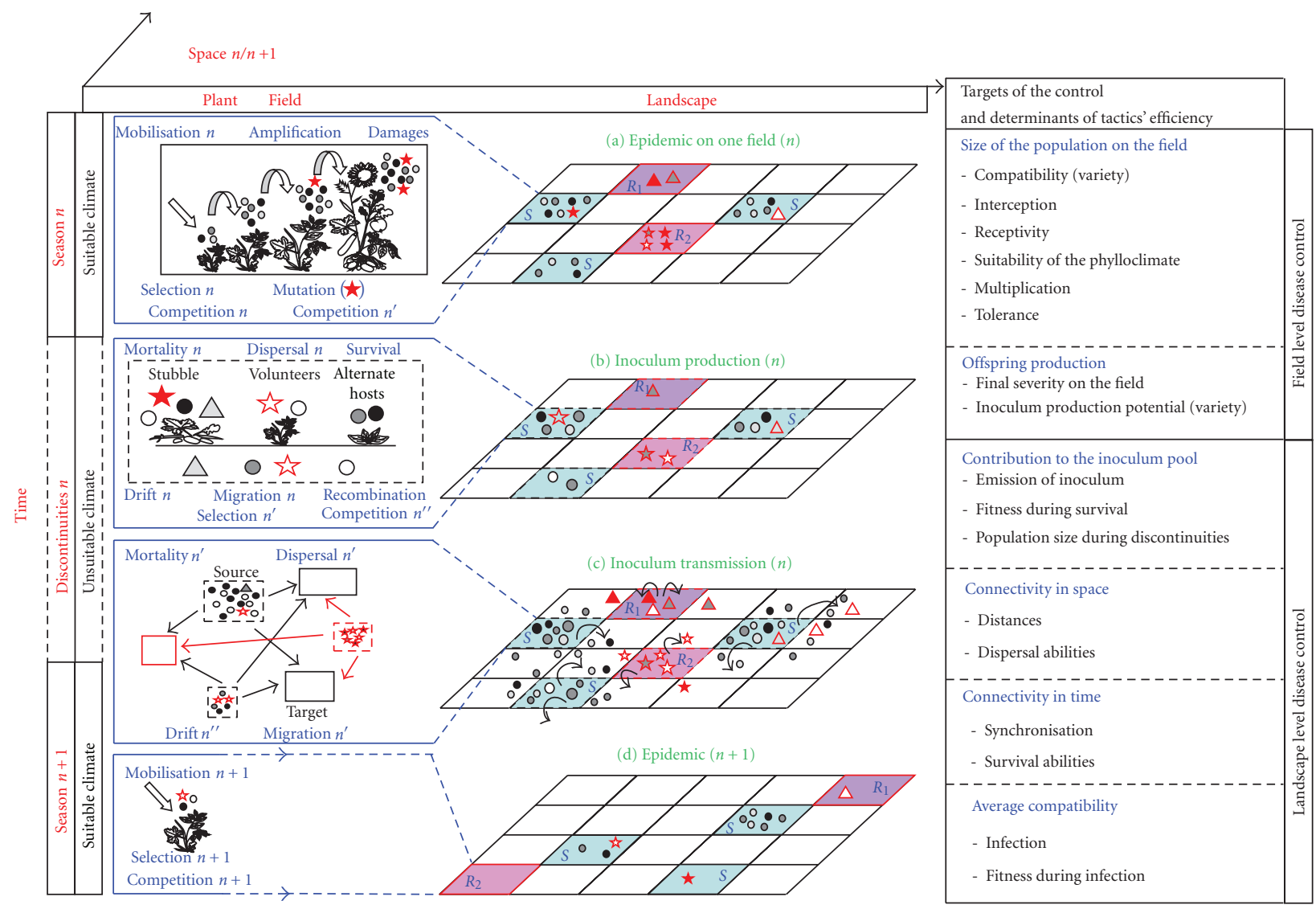

Figure 2: Determinants of disease control efficacy on one field and in the landscape based on a schematic representation of pluriannual dynamics of cyclic epidemics of plant diseases in an agroecosystem. The agroecosystem is defined on scales of space and time by the alternation of homogeneities and heterogeneities induced by agricultural practices. The "pluriannual epidemics"-represented for seasons $(n)$ and $(n+1)$-is defined as the succession of (a) within field epidemics, (b) production of inoculum on the field, (c) transmission of inoculum from source to target fields, and (d) within field epidemics in the following season. The processes defined by life cycle and genetics affect pathogen population size or structure (above and below encapsulated panels, resp.). Different letters $\left(n, n^{\prime}, n^{\prime \prime}\right)$ indicate that the successive realisation of processes can be independent. For each component of the pluriannual epidemics, a limited number of attributed aims (listed on the right) determine the efficacy of disease control tactics. The diversity of individuals within pathogen populations is represented by the different shading of the symbols, illustrated with respect to plant resistance. The efficacy of disease reduction on susceptible $(S)$ and resistant varieties $\left(R_{1}, R_{2}\right)$ depends on the host and pathogen populations properties (listed on the right) in the landscape that it is possible to manage.

the pathogen population [26]. Thus, if the disease control is at stake in the context of agroecosystems, epidemiological concepts need adjustment to take into account simultaneously both actors' actions and discontinuities.

\section{How to Formalize the Dynamics of Cyclic Epidemics in Agroecosystems?}

Formalisation is well established in the continuous space consisting of the scale of one season in one field. Population numerical dynamics is described by initial inoculum and multiplication rate [5]. Population spatial dynamics is described by the theory of disease foci [6]. In the context of agroecosystems, the existence of sharp ruptures hampers the extension of these concepts over wider scales of time and space. Releasing the hypothesis of continuity has been achieved for time, by taking into account seasonality [38]; for space, by taking into account heterogeneous landscape [3942]; for the continuity of epidemics, by taking into account human actions [43-45], but these aspects have not yet been formalised simultaneously.

The alternation of continuities and ruptures on scales of time and space allows describing the pluriannual dynamics by three phases (Figure 2 (central column)): the epidemics on one field, the inoculum production on the field, and the inoculum transmission between fields. Within each phase, the processes affecting population size or structure at lower scales of space (the field, the plant, and the vegetal organ) and time (the season and the duration of one pathogen generation) scales can be aligned (Figure 2 (left column)).

The within field epidemic dynamic, that is, the quantitative fluctuations of size and the qualitative changes in genetic structure of the pathogen population, can be described by 
three time-chained or overlapping components within the season (Figure 2(a)). The local onset of the epidemic in the field requires mobilisation of propagules from a more or less distant inoculum pool connected to the field by migration [46]; The pathogen population increases in size during the epidemic by secondary multiplication cycles [47]; The pathogen population causes damages to plants, defined as the qualitative or quantitative yield loss caused by the disease, with subsequent economical consequences for farmers [48].

The production of inoculum during discontinuities in each field (Figure 2(b)) occurs either on the same plants [49], or requires the infection of volunteer plants $[19,49]$, or necessitate migration to alternate hosts [49]. This production of inoculum depends on the within field epidemics [50]. Offspring release and contribution to the propagule pool in subsequent seasons depend on the pathogen's survival abilities [43].

The inoculum transmission between fields (Figure 2(c)) coincides with intercrop discontinuities and depends on characteristics of both "source" and "target" fields, and on landscape spatial and temporal structures [49]. Field characteristics for the source are the quantity and characteristics of the inoculum released; and for the targets, the host crop status and variety. Structure of the landscape includes for its spatial aspect, the location of new fields and the selection pressure they impose; for its temporal aspect, the time at which fields are sown and are susceptible to infection. The inoculum transmission phase results in strong quantitative (size) and qualitative (genetic structure) variations in pathogen populations.

In agroecosystems, the prospect is offered to maximise the efficiency of disease control by using human actions to interfere with the cyclic epidemic, both during the epidemic phases and during the survival phases.

\section{How to Link the Control of Epidemics to Their Pluriannual Dynamics?}

In crop production systems, the pathogen populations constrain the maximum harvestable productivity of plants [48]. To control epidemics, several agronomic disciplines apply different control "tactics". By "tactic" we refer to the means, issued from human choices, to interfere with the epidemics. Tactics can aim at reducing size, and/or at modifying the genetic composition of the pathogen population on the field. To identify and coordinate each' one's contributions, sorting out the complexity can be achieved by taking into account the ruptures in epidemiological processes (Figure 2 (right column)). To include these discontinuities, we will distinguish field level disease control, that is, benefits obtained on one field resulting from actions on that field, and landscape level disease control, that is, benefits obtained on one field resulting from actions on the landscape in which this field is located. Furthermore, disease management can be dissected into processes, hereafter "attributed aims", each corresponding to one component of the pluriannual epidemic described above (Figure 2 (right column)).
Field Level Disease Control. (Figure 2(ab)) acts on:

(i) the compatibility of the interaction between pathogen and plant individuals, that determines infection. Compatibility encompasses both infectivity and virulence (respectively virulence/aggressiveness in plant pathology; [51]) because qualitative all or nothing abilities represent the two edges of the continuum;

(ii) the interception by the plant, given passive or active deposition of propagules from the local pool. Interception depends on plant architecture, including topology, phenology, leaf structure, and on attractiveness for vectors [5];

(iii) the receptivity of the host tissue allowing for infection. Receptivity depends on biocide or repellent application, leaf structure and ontogenic resistance;

(iv) the suitability of the phylloclimate [52] allowing for infection. Suitability depends on temperature-related or humidity-related propagule viability and infectiousness;

(v) the multiplication depending on the interaction between the host growth, the pathogen lifecycle and the climate. Multiplication can be figured out as the ratio of daughter propagules per mother lesion during the epidemics on the field. Multiplication depends on the duration of one generation and on multiplication rates [7];

(vi) the tolerance, which is the capacity of the host plant to incur less damage at a given infection severity [53];

(vii) the offspring production, which is the ratio of daughter propagules that can serve as inoculum for the next season, per mother lesion. Offspring production depends on the final disease severity at the end of the epidemics on the field [50].

Landscape Level Disease Control. (Figure 2(bcd)), assuming integration-in the mathematical sense of the word-over "source" and "target" fields, acts on:

(i) the offspring contribution to the spore pool, allowing for inoculum build-up. Offspring contribution depends on the size of the population established on the acreage of host species and on the inoculum emission [54];

(ii) the connectivity in space, allowing for transmission. Connectivity in space depends on the pathogen's dispersal ability, on distances and on barriers to flow $[22,55]$;

(iii) the connectivity in time, allowing for transmission. Connectivity in time depends on the pathogen's survival ability and on the synchronisation of source emission and target receptivity [49];

(iv) the average compatibility of the pathogen population on the host plant population. Average compatibility depends on compatibilities between source-target pairs and on the connectivity in space and in time 
$[15,54]$. Any landscape scale tactic reducing these processes will help increase field scale disease management $[15,55-57]$.

"Efficiency" of disease control relates to the reduction of damage in one season in one field with disease management compared to the same field in a landscape consisting of only susceptible varieties without disease management. Optimising the efficiency of disease control relies on a strategic combination of tactics.

\section{Optimising the Efficiency of the Control of Epidemics: Interdisciplinary Collaborations and Key Points for Research}

The control of epidemics is focal point of several scientific disciplines. The prospect of our work is allowing for a better definition of roles towards easier interdisciplinary exchanges. The networking between concepts by relating them to the dynamics of pluriannual epidemics in agroecosystems (Figure 2) yield the benefits to combine tactics issued from different scientific disciplines for each of the "attributed aims" [57], for example plant genetics devises breeding strategies to reduce pathogens' impacts on the plant. Agronomy devises on the one hand, cultivation practices related to plant physiology; on the other hand, cropping systems related to the organisation of farms and of production systems. Plant pathology deciphers the determinants of the pathogen interaction with the host plant and describes the life cycle of the pathogen. The articulation of the whole set of concepts will promote information exchange by precision of terms [58]. This new light on epidemiology in agroecosystems could facilitate communication by enabling articulation between theory, empirical studies, and actors' knowledge. Positioning disciplines and actors' roles could optimise their complementarities. Clarifying interactions between concepts could optimise pluridisciplinary. Therefore, when an agroecosystem faces a disease management problem, assembled concepts (Figure 2) could be used to describe the local situation, to identify what is known and what is practiced, taking into account all actors and all disciplines. In this agroecosystem at that moment, the multidimensional set of constraints-including what is known and what is not-could be used to discern ways to increase efficiency of the control of epidemics, relatively to their costs.

The first key point for research is the acquisition of empirical data on processes of the life cycles of the pathogens. For polyetic epidemics, data have been collected during the epidemic phases in successive years. The analysis of the progression dynamics on long-term scales have allowed to take into account survival and transmission without being obliged to quantify these processes directly. In the case of cyclic epidemics, because of the stability over long-term scales of time, this approach will not be possible. It will be necessary to acquire data during the discontinuity phases, to understand the processes occurring between two successive seasons (Figure 2). This especially concerns the phase of production of inoculum [50,59] of survival [43] as well as transmission between fields of different seasons [41]. This will, for example, allow revising intercrop agronomical practices [60] to understand their impact through the amount of inoculum produced and transmitted.

The second key point for research concerns the theoretical developments about cyclic epidemics on crops, in two directions. On the one hand, the theoretical analysis of polyetic epidemics allowed defining criteria for invasion and persistence of pathogens [29]. Similarly, the theoretical study of cyclic epidemics will allow determining criteria for the limitation of interannual variability, or to maintain these epidemics under damage thresholds. On the other hand, theoretical studies can be connected with these of cyclic epidemics in human and in animals [34] and pests [35].

The third key point for research concerns the possible junction between epidemiology and evolution, rendered possible by the explicit description of the pluriannual dynamics of the epidemics (Figure 2). This opens the prospect of stronger connections between epidemiology, population genetics, and evolutionary biology $[61,62]$. On the one hand, the recurrent nature (in time) of cyclic epidemics allows for the description of the phases during which variations are produced, selected, and transmitted. We have illustrated this by the alignment of processes affecting the size, with these affecting the composition of pathogen populations, for each of the components of the dynamics (Figure 2 (left column)). On the other hand, making explicit the homogeneities and heterogeneities allows junction with the analysis of evolutionary processes. It will be possible to analyse under this light the ambivalent nature of pathogen life cycles during epidemic phases and discontinuities, respectively. [25]. On longer term, evolutionary epidemiology formalised at the level of the landscape can be connected to landscape ecology $[33,55]$ with levers of action on epidemics by land planning.

\section{How to Reach a Solution despite the High Level of Complexity?}

The high level of complexity following from the large number of interacting elements leads to an antagonism; theory has to be inclusive of all aspects but studies have to be parsimonious. Achieving the articulation of the whole set of disciplinary concepts (Figure 2) allows to realize that simultaneous understanding of all factors is beyond reach, therefore beyond prediction. There is no single, general, and unique solution that can be studied and reached. On the contrary, the optimal balance depends on the "local" situation in time and in space. By "local", we refer to the cropped species, the biology of pathogens, the production situations, and the available tactics. The question that arises is: should one simplify upstream and look for one unique strategy to be recommended in a centralised manner, or simplify downstream and allow for the decentralised implementation of local strategies?

At the field scale, scientists have produced one single comprehensive theoretical framework. Within, all the concepts necessary to understand the numerical and spatial dynamics of epidemics were articulated $[5,6]$. However, the amount of complexity was already too high to include all factors in one model or to look for one unique solution 
appropriate for all local situations. Nevertheless, fruitful collaborations-interdisciplinary researches as well as interactions between research and implementation by actorshave been built upon simplifications. We refer to simplification as a clever choice of a reduced number of factors, focussing on these relevant for the local situation.

At the landscape scale, the control of epidemics within the conceptual framework of polyetic epidemics has been based on the optimal control strategy. It is based upon an a priori modelling, from which a centralised control strategy could be devised. When the concern is biological invasionthe emergence of a pathogen previously absent from the area-its eradication [63] may require the design of a uniform and centralised strategy. The assumption underlying centralized disease management is that scientists are able to identify and stakeholders able to choose the best strategy ahead of applying it. The costs to collect the necessary information with sufficient accuracy may be justified by the perspective of eradication which, on the one hand, requires early intervention and on the other hand has to be performed before empirical knowledge of actors could be accumulated, because the disease was previously absent. Key point for research is to connect optimal control theory of crop pathogens $[28,64]$ with that of humans and animals [34, 65-67].

However, at the landscape scale, the conceptual framework of cyclic epidemics opens an alternative prospect for the control of epidemics, based on upstream implication of actors' knowledge and local simplification. For those cyclic epidemics of already established pathogens, eradication is out of reach. The interaction between host plant and pathogens over large scales of space and time promotes the differentiation of local contexts, for example, for the presence of inoculum sources scarce or numerous [30]. On the one hand, the cost of collecting the necessary information with sufficient accuracy and the development of models for each of the specific local contexts increases in proportion of the diversity of local situations. On the other hand, repeated confrontation with the locally established pathogens promotes the development, improvement, and accumulation of actors' empirical knowledge. This opens the prospect of local optimisation for a local and decentralised disease control. The hypothesis underlying decentralised disease control is that it is possible to locally combine actors' knowledge and guidelines based on scientific knowledge. This allows adjusting over time the control strategy to the real local situation by successive back and forth rounds. It is of note that for human pathogens, disease control of cyclic epidemics relies on education to hygiene. Learning of early detection of symptoms allows for increase in individuals' ability to perform informed decentralised choices, helped if necessary by doctors. Transposing this approach to agriculture assumes to rely on farmers, letting them develop their ability to collect local information in real time. For crop pathogens and pests, supporting ecologically informed decision making by farmers has been achieved by education to address the challenge of ecological heterogeneity and local specificity in disease management [68]. The role of scientists remains to understand the principles of biological processes and propose guidelines for a decentralised choice. Key points for research towards local optimisation approaches include studies of joint optimisation of several criteria [69], or optimisation under constraints [70], the coexistence of several strategies in the same agroecosystem [71].

To conclude, we advocate that a shared description of processes pertinent to any kind of epidemics highlights the need for specific researches. Cyclic epidemics are different from polyetic epidemics and could therefore be managed in a different way, even if it is not excluded that decentralised strategies could also be appropriate for polyetic epidemics. We expect our perspective on this network to trigger pluridisciplinary research and fair interactions between scientists and actors in tomorrow's Agroecosystems.

\section{Acknowledgments}

The authors thank F. Fabre, C. Lannou, E. Lô-Pelzer, I. Sache and N. Sapoukhina for fruitful discussions. S. Bouhallab, L. Gebbie and B. Chevassus-au-Louis helped improving the manuscript. This work benefited from financial support of INRA and ANR - the French National Research Agencyprogram "Agriculture et Développement Durable" Grant "ANR-05-PADD-05, CEDRE."

\section{References}

[1] Millenium Ecosystem Assessment (MEA), "Appendix DGlossary," in Current State and Trends Assessment, vol. 1, Island Press, Washington, DC, USA, 2005.

[2] O. L. Loucks, "Emergence of research on agro-ecosystems," Annual Review of Ecology and Systematics, vol. 8, pp. 73-192, 1977.

[3] J. Pretty, "Agricultural sustainability: concepts, principles and evidence," Philosophical Transactions of the Royal Society B, vol. 363, no. 1491, pp. 447-465, 2008.

[4] C. Stoate, A. Báldi, P. Beja et al., "Ecological impacts of early 21st century agricultural change in europe-a review," Journal of Environmental Management, vol. 91, no. 1, pp. 22-46, 2009.

[5] G. Agrios, Plant Pathology, Elsevier-Academic Press, San Diego, Calif, USA, 5th edition, 2005.

[6] J. C. Zadoks and F. Van den Bosch, "On the spread of plant disease: a theory on foci," Annual Review of Phytopathology, vol. 32, pp. 503-521, 1994.

[7] L. V. Madden, G. Hughes, and F. van den Bosch, The Study of Plant Disease Epidemics, APS Press, St. Paul, Minn, USA, 2006.

[8] H. A. McCartney and B. D. L. Fitt, "Dispersal of fungal plant pathogens: mechanisms, gradients and spatial patterns," in Plant Disease Epidemiology, G. Jones, Ed., pp. 138-160, Kluwer Academic, London, UK, 1998.

[9] S. Soubeyrand, J. Enjalbert, A. Sanchez, and I. Sache, "Anisotropy, in density and in distance, of the dispersal of yellow rust of wheat: experiments in large field plots and estimation," Phytopathology, vol. 97, no. 10, pp. 1315-1324, 2007.

[10] B. Hau, "Analytic models of plant disease in a changing environment," Annual Review of Phytopathology, vol. 28, pp. 221245, 1990.

[11] M. S. Wolfe and E. Schwarzbach, "Patterns of race changes in powdery mildews," Annual Review of Phytopathology, vol. 16, pp. 159-80, 1978.

[12] J. E. Parlevliet, "Components of resistance that reduce the rate of epidemic development," Annual Review of Phytopathology, vol. 17, pp. 203-222, 1979. 
[13] A. Newton, N. McRoberts, and G. Hughes, "Information technology in plant disease epidemiology," in The Epidemiology of Plant Diseases, B. M. Cooke, D. G. Jones, and B. Kaye, Eds., pp. 335-356, Springer, Dordrecht, The Netherlands, 2nd edition, 2006.

[14] M. S. Hovmoller, V. Caffier, M. Jalli et al., "The european barley powdery mildew virulence survey and disease nursery 1993-1999," Agronomie, vol. 20, no. 7, pp. 729-743, 2000.

[15] M. R. Finckh and M. S. Wolfe, "Diversification strategies," in The Epidemiology of Plant Diseases, B. M. Cooke, D. G. Jones, and B. Kaye, Eds., pp. 269-308, Springer, Dordrecht, The Netherlands, 2nd edition, 2006.

[16] B. A. McDonald and C. Linde, "Pathogen population genetics, evolutionary potential, and durable resistance," Annual Review of Phytopathology, vol. 40, pp. 349-379, 2002.

[17] A. Palloix, V. Ayme, and B. Moury, "Durability of plant major resistance genes to pathogens depends on the genetic background, experimental evidence and consequences for breeding strategies," New Phytologist, vol. 183, no. 1, pp. 190-199, 2009.

[18] H. Brun, A. M. Chèvre, B. D. Fitt et al., "Quantitative resistance increases the durability of qualitative resistance to Leptosphaeria maculans in Brassica napus," New Phytologist, vol. 185, no. 1, pp. 285-299, 2010.

[19] J. C. Zadoks, "Reflections on space, time, and diversity," Annual Review of Phytopathology, vol. 37, pp. 1-17, 1999.

[20] M. J. Jeger, "Analysis of disease progress as a basis for evaluating disease management practices," Annual Review of Phytopathology, vol. 42, pp. 61-82, 2004.

[21] G. A. Forbes, E. S. G. Mizubuti, and D. Shtienberg, "Plant disease epidemiology and disease management-has science had an impact on practice?" in Integrated Pest Management: Innovation-Development Process, R. Peshin and A. K. Dahwan, Eds., pp. 347-364, Springer Science, Business Media B.V., 2009.

[22] C. A. Gilligan, J. E. Truscott, and A. J. Stacey, "Impact of scale on the effectiveness of disease control strategies for epidemics with cryptic infection in a dynamical landscape: an example for a crop disease," Journal of the Royal Society Interface, vol. 4, no. 16, pp. 925-934, 2007.

[23] R. S. Ostfeld, G. Glass, and F. Keesing, "Spatial epidemiology: an emerging (or re-emerging) discipline," Trends in Ecology and Evolution, vol. 20, no. 6, pp. 328-336, 2005.

[24] M. Plantegenest, C. Le May, and F. Fabre, "Landscape epidemiology of plant diseases," Journal of the Royal Society Interface, vol. 4, no. 16, pp. 963-972, 2007.

[25] E. H. Stukenbrock and B. A. McDonald, "The origins of plant pathogens in agro-ecosystems," Annual Review of Phytopathology, vol. 46, pp. 75-100, 2008.

[26] J. C. Zadoks and R. D. Schein, Epidemiology and Plant Disease Management, Oxford University Press, New York, NY, USA, 1979.

[27] W. Otten, D. J. Bailey, and C. A. Gilligan, "Empirical evidence of spatial thresholds to control invasion of fungal parasites and saprotrophs," New Phytologist, vol. 163, no. 1, pp. 125-132, 2004.

[28] G. Forster and C. A. Gilligan, "Optimizing the control of disease infestations at the landscape scale," Proceedings of the National Academy of Sciences of the United States of America, vol. 104, no. 12, pp. 4984-4989, 2007.

[29] C. A. Gilligan and F. van den Bosch, "Epidemiological models for invasion and persistence of pathogens," Annual Review of Phytopathology, vol. 46, pp. 385-418, 2008.

[30] S. Parnell, T. R. Gottwald, F. van den Bosch, and C. A. Gilligan, "Optimal strategies for the eradication of asiatic citrus canker in heterogeneous host landscapes," Phytopathology, vol. 99, no. 12, pp. 1370-1376, 2009.

[31] S. Parnell, T. R. Gottwald, C. A. Gilligan, N. J. Cunniffe, and F. van den Bosch, "The effect of landscape pattern on the optimal eradication zone of an invading epidemic," Phytopathology, vol. 100, no. 7, pp. 638-644, 2010.

[32] T. Václavík, A. Kanaskie, E. M. Hansen, J. L. Ohmann, and R. K. Meentemeyer, "Predicting potential and actual distribution of sudden oak death in oregon: prioritizing landscape contexts for early detection and eradication of disease outbreaks," Forest Ecology and Management, vol. 260, no. 6, pp. 1026-1035, 2010.

[33] M. Moslonka-Lefebvre, A. Finley, I. Dorigatti et al., "Networks in plant epidemiology: from genes to landscapes, countries, and continents," Phytopathology, vol. 101, no. 4, pp. 392-403, 2011.

[34] M. C. Boerlijst and W. M. van Ballegooijen, "Spatial pattern switching enables cyclic evolution in spatial epidemics," Plos Computational Biology, vol. 6, no. 12, Article ID e1001030, 2010.

[35] J. U. Jepsen, S. B. Hagen, S. R. Karlsen, and R. A. Ims, "Phasedependent outbreak dynamics of geometrid moth linked to host plant phenology," Proceedings of the Royal Society B, vol. 276, no. 1676, pp. 4119-4128, 2009.

[36] H. M. Alexander, "Disease in natural plant populations, communities, and ecosystems: insights into ecological and evolutionary processes," Plant Disease, vol. 94, no. 5, pp. 492-503, 2010.

[37] C. E. Morris, M. Bardin, L. L. Kinkel, B. Moury, P. C. Nicot, and D. C. Sands, "Expanding the paradigms of plant pathogen life history and evolution of parasitic fitness beyond agricultural boundaries," Plos Pathogens, vol. 5, no. 12, Article ID e1000693, 2009.

[38] F. Van Den Berg, C. A. Gilligan, D. J. Bailey, and F. Van Den Bosch, "Periodicity in host availability does not account for evolutionary branching as observed in many plant pathogens: an application to gaeumannomyces graminis var. tritici," Phytopathology, vol. 100, no. 11, pp. 1169-1175, 2010.

[39] D. E. Aylor, "Biophysical scaling and the passive dispersal of fungus spores: relationship to integrated pest management strategies," Agricultural and Forest Meteorology, vol. 97, no. 4, pp. 275-292, 1999.

[40] J. Holt and T. C. B. Chancellor, "Modelling the spatio-temporal deployment of resistant varieties to reduce the incidence of rice tungro disease in a dynamic cropping system," Plant Pathology, vol. 48, no. 4, pp. 453-461, 1999.

[41] P. Skelsey, W. A. H. Rossing, G. J. T. Kessel, and W. van der Werf, "Invasion of phytophthora infestans at the landscape level: how do spatial scale and weather modulate the consequences of spatial heterogeneity in host resistance?" Phytopathology, vol. 100, no. 11, pp. 1146-1161, 2010.

[42] C. C. Mundt, K. E. Sackett, and L. D. Wallace, "Landscape heterogeneity and disease spread: experimental approaches with a plant pathogen," Ecological Applications, vol. 21, no. 2, pp. 321-328, 2011.

[43] C. G. Kocks, M. A. Ruissen, J. C. Zadoks, and M. G. Duijkers, "Survival and extinction of xanthomonas campestris pv. campestris in soil," European Journal of Plant Pathology, vol. 104, no. 9, pp. 911-923, 1998.

[44] S. Parnell, F. van den Bosch, and C. A. Gilligan, "Large-scale fungicide spray heterogeneity and the regional spread of resistant pathogen strains," Phytopathology, vol. 96, no. 5, pp. 549-555, 2006.

[45] F. Behlau, L. Amorim, J. Belasque et al., "Annual and polyetic progression of citrus canker on trees protected with copper sprays," Plant Pathology, vol. 59, no. 6, pp. 1031-1036, 2010. 
[46] H. A. McCartney, B. D. L. Fitt, and J. S. West, "Dispersal of foliar plant pathogens: mechanisms, gradients and spatial patterns," in The Epidemiology of Plant Diseases, B. M. Cooke, D. G. Jones, and B. Kaye, Eds., pp. 159-192, Springer, Dordrecht, The Netherlands, 2nd edition, 2006.

[47] M. W. Shaw, "Pathogen population dynamics," in The Epidemiology of Plant Diseases, B. M. Cooke, D. G. Jones, and B. Kaye, Eds., pp. 269-308, Springer, Dordrecht, The Netherlands, 2nd edition, 2006.

[48] S. Savary, P. S. Teng, L. Willocquet, and F. W. Nutter, "Quantification and modeling of crop losses: a review of purposes," Annual Review of Phytopathology, vol. 44, pp. 89-112, 2006.

[49] R. J. Cook and D. J. Yarham, "Epidemiology in sustainable systems," in The Epidemiology of Plant Diseases, B. M. Cooke, D. G. Jones, and B. Kaye, Eds., pp. 309-334, Springer, Dordrecht, The Netherlands, 2nd edition, 2006.

[50] E. Lô-Pelzer, J. N. Aubertot, O. David, M. H. Jeuffroy, and L. Bousset, "Relationship between severity of blackleg (leptosphaeria maculans/l. biglobosa species complex) and subsequent primary inoculum production on oilseed rape stubble," Plant Pathology, vol. 58, no. 1, pp. 61-70, 2009.

[51] S. Sacristán and F. García-Arenal, "The evolution of virulence and pathogenicity in plant pathogen populations," Molecular Plant Pathology, vol. 9, no. 3, pp. 369-384, 2008.

[52] M. Chelle, "Phylloclimate or the climate perceived by individual plant organs: what is it? how to model it? what for?" New Phytologist, vol. 166, no. 3, pp. 781-790, 2005.

[53] M. L. Deadman, "Epidemiological consequences of plant disease resistance," in The Epidemiology of Plant Diseases, B. M. Cooke, D. G. Jones, and B. Kaye, Eds., pp. 139-158, Springer, Dordrecht, The Netherlands, 2nd edition, 2006.

[54] M. S. Hovmøller, H. Østergård, and L. Munk, "Modelling virulence dynamics of airborne plant pathogens in relation to selection by host resistance in agricultural crops," in The Gene-for-Gene Relationship in Host-Parasite Interactions, I. R. Crute, J. J. Burdon, and E. B. Holub, Eds., pp. 173-190, CAB International, Wallingford, UK, 1997.

[55] M. L. Margosian, K. A. Garrett, J. M. S. Hutchinson, and K. A. With, "Connectivity of the american agricultural landscape: assessing the national risk of crop pest and disease spread," Bioscience, vol. 59, no. 2, pp. 141-151, 2009.

[56] J. M. Krupinsky, K. L. Bailey, M. P. McMullen, B. D. Gossen, and T. Kelly Turkington, "Managing plant disease risk in diversified cropping systems," Agronomy Journal, vol. 94, no. 2, pp. 198-209, 2002.

[57] E. Lô-Pelzer, L. Bousset, M. H. Jeuffroy et al., "Sippom-wosr: a simulator for integrated pathogen population management of phoma stem canker on winter oilseed rape. I. Description of the model," Field Crops Research, vol. 118, no. 1, pp. 73-81, 2010.

[58] R. K. Plowright, S. H. Sokolow, M. E. Gorman, P. Daszak, and J. E. Foley, "Causal inference in disease ecology: investigating ecological drivers of disease emergence," Frontiers in Ecology and the Environment, vol. 6, no. 8, pp. 420-429, 2008.

[59] L. Bousset, H. Brun, A. M. Chèvre, and R. Delourme, "Quel lien entre l'épidémiologie, la création variétale et le potentiel de durabilité des résistances ? Illustration chez le phoma du colza," Innovations Agronomiques, vol. 15, pp. 31-45, 2011.

[60] G. Daverdin, Evolution moléculaire sous pression de sélection et implication dans la reconnaissance AvrLm3/Rlm3 du gène d'avirulence AvrLm4-7 chez Leptosphaeria maculans, Ph.D. thesis, Université Paris XI Orsay, 2011.

[61] K. Shea, P. H. Thrall, and J. J. Burdon, "An integrated approach to management in epidemiology and pest control," Ecology Letters, vol. 3, no. 2, pp. 150-158, 2000.
[62] E. A. Archie, G. Luikart, and V. O. Ezenwa, "Infecting epidemiology with genetics: a new frontier in disease ecology," Trends in Ecology and Evolution, vol. 24, no. 1, pp. 21-30, 2009.

[63] M. R. Sosnowski, J. D. Fletcher, A. M. Daly, B. C. Rodoni, and S. L. H. Viljanen-Rollinson, "Techniques for the treatment, removal and disposal of host material during programmes for plant pathogen eradication," Plant Pathology, vol. 58, no. 4, pp. 621-635, 2009.

[64] M. L. Ndeffo-Mbah and C. A. Gilligan, "Optimization of control strategies for epidemics in heterogeneous populations with symmetric and asymmetric transmission," Journal of Theoretical Biology, vol. 262, no. 4, pp. 757-763, 2010.

[65] S. Riley, "Large-scale spatial-transmission models of infectious disease," Science, vol. 316, no. 5829, pp. 1298-1301, 2007.

[66] J. C. Koella, P. A. Lynch, M. B. Thomas, and A. F. Read, "Towards evolution-proof malaria control with insecticides," Evolutionary Applications, vol. 2, no. 4, pp. 469-480, 2009.

[67] A. Litvak-Hinenzon and L. Stone, "Spatio-temporal waves and targeted vaccination in recurrent epidemic network models," Journal of the Royal Society Interface, vol. 6, no. 38, pp. 749760, 2009.

[68] A. Braun, J. Jiggins, N. Röling, H. van den Berg, and P. Snijders, "A Global Survey and Review of Farmer Field School Experiences," Report prepared for the International Livestock Research Institute (ILRI). Global Farmer Field School Network and Research Centre, 2006, http://www .share4dev.info/ffsnet/output_view.asp?outputID $=1880$.

[69] W. Sadok, F. Angevin, J. E. Bergez et al., "Masc, a qualitative multi-attribute decision model for ex ante assessment of the sustainability of cropping systems," Agronomy for Sustainable Development, vol. 29, no. 3, pp. 447-461, 2009.

[70] R. B. Gramacy and H. K. H. Lee, "Optimization under unknown constraints," arXiv:1004.4027v2.

[71] Y. Devos, M. Demont, K. Dillen, D. Reheul, M. Kaiser, and O. Sanvido, "Coexistence of genetically modified (gm) and non-gm crops in the european union. a review," Agronomy for Sustainable Development, vol. 29, no. 1, pp. 11-30, 2009. 

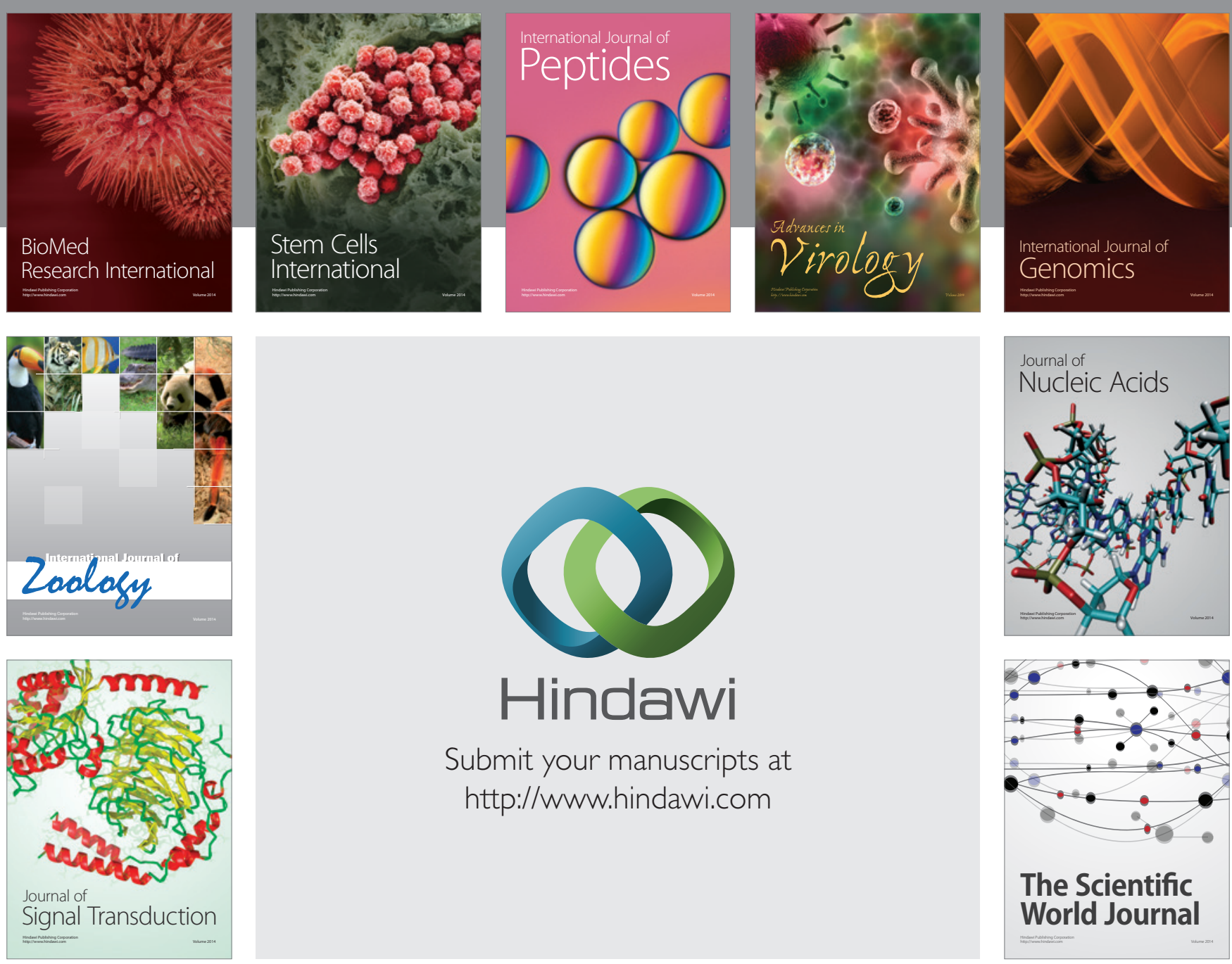

Submit your manuscripts at

http://www.hindawi.com
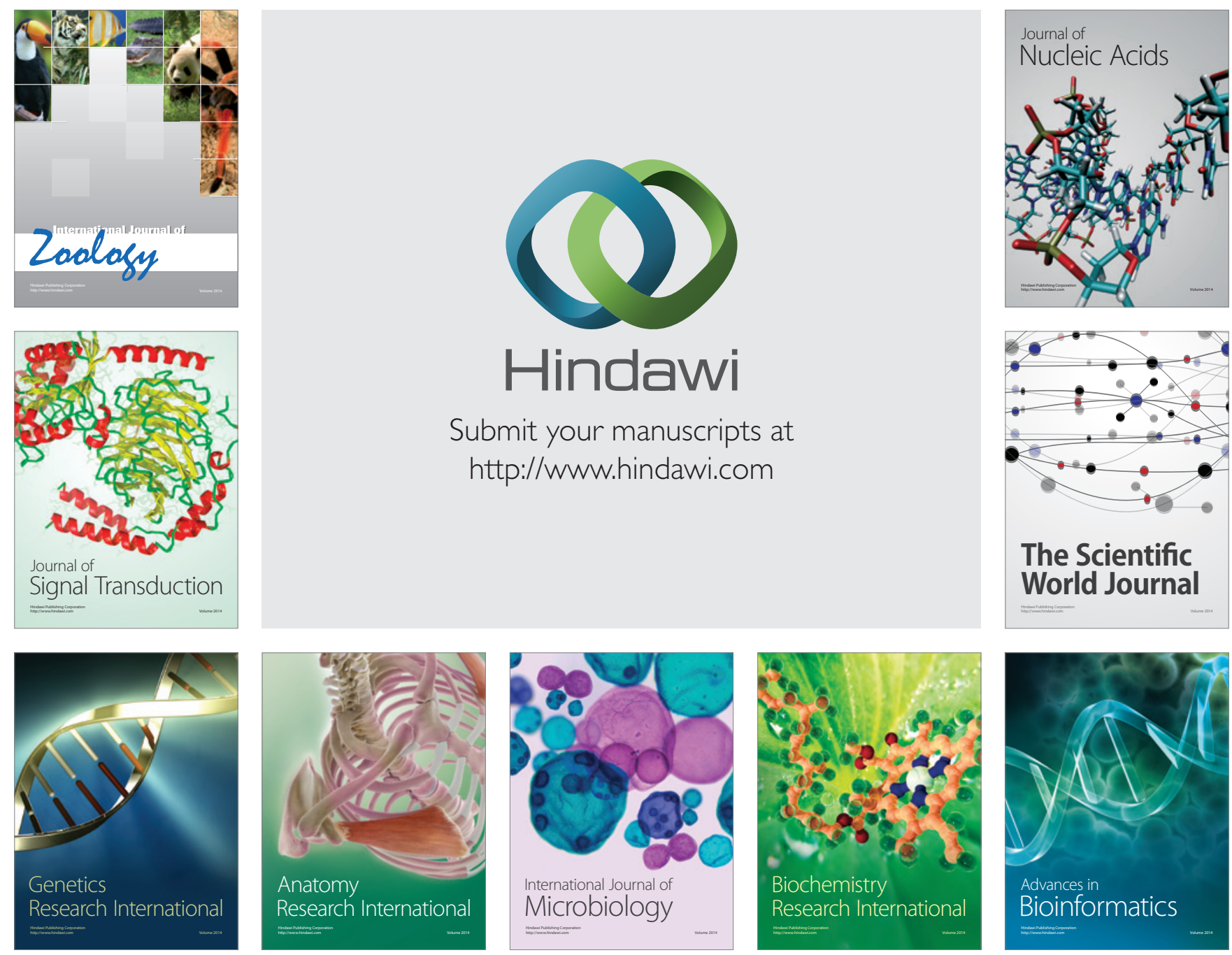

The Scientific World Journal
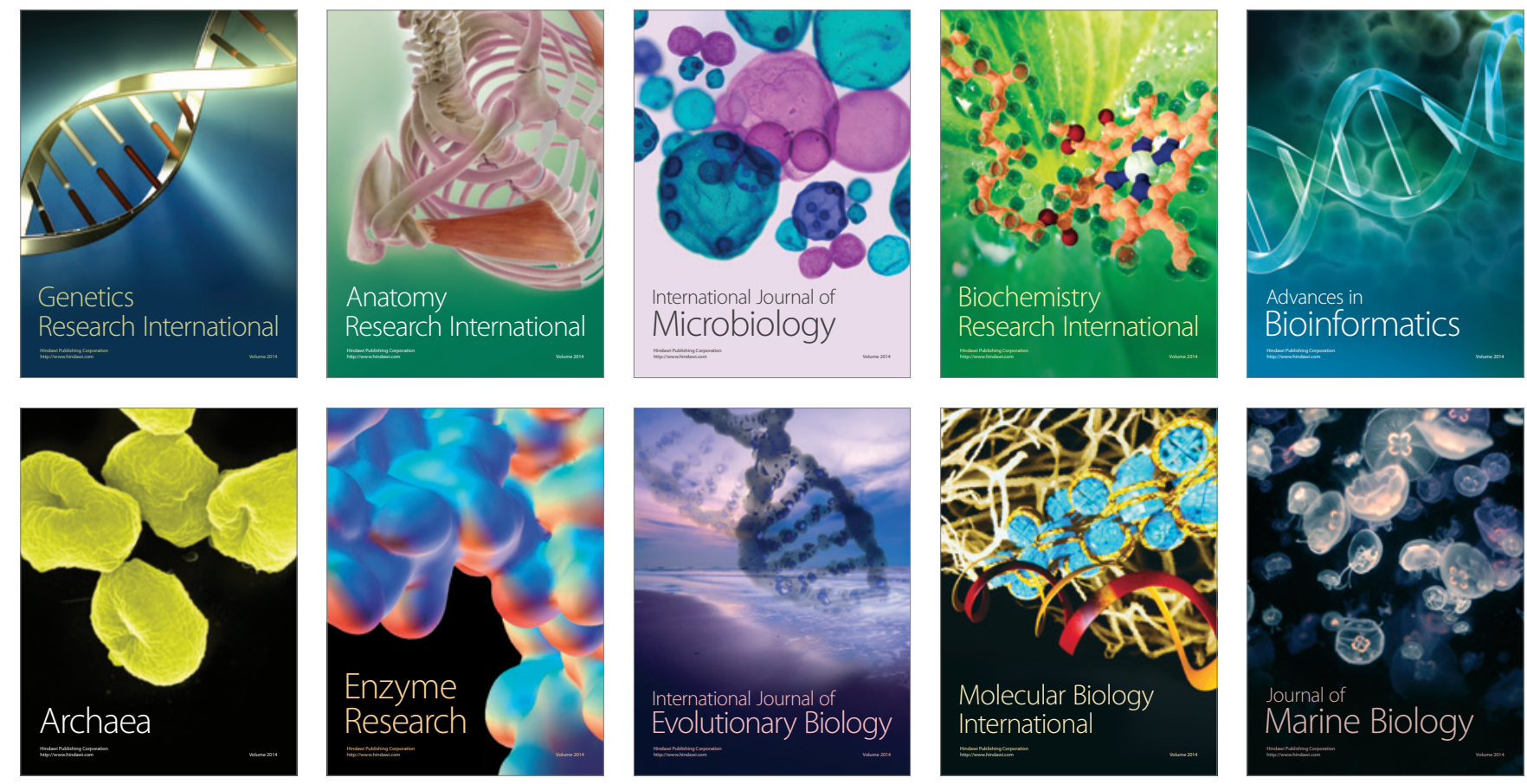